\title{
Inductive Engineering and Its Application in Product Design
}

\author{
Li Zhou
}

Hankou University, Wuhan, Hubei, 430212

Keywords: Inductive Engineering, Application Research, Production Design

\begin{abstract}
With the advancement of science and technology, rich social production has been able to meet people's demand for mass and functional products, consumers increasingly emphasize the product's emotional experience and personality differences, the purchase decision is also more emotional and The impact of psychological needs. For enterprises, the era of technology homogenization of the times, making the technical advantages in winning the market competition is no longer so effective, companies must find new ways to make their products easy to identify. Through a variety of ways to enhance the product of the consumer's emotional and spiritual care has gradually become the design community to pursue the product design direction.
\end{abstract}

\section{Introduction}

Inductive engineering aims to systematically explore the emotional response to the product and translate it into the product design elements. It provides designers and manufacturers with a product quality and function is quite the case to enhance the competitive advantage of the design method. The principle of perceptual engineering is: the designer through the observation method, physiological or psychological measurement method, to master the consumer's emotional needs of the product, and through a variety of engineering methods to establish such needs and product design elements of the relationship between the most Good combination of design elements. Therefore, a great advantage of perceptual engineering is to be able to a variety of product characteristics and consumer emotional and psychological needs linked to the final design to meet the consumer's psychological and emotional needs of the product. It can be seen that perceptual engineering is a new design method that adapts to the changing trend of consumer demand and design concept. The combination with engineering makes the method stronger and wider. For more than 30 years, the research and application of perceptual engineering have matured and have penetrated into the whole Japanese industry. European countries, the United States, South Korea and Taiwan have also begun to learn this technology earlier. In short, as a measure of the degree of consumer awareness of the scale of the consumer, emotional engineering in the design community more and more attention, the technology in the field of product design will have a very broad application prospects, its research and application will bring a good economy And social benefits.

\section{The Meaning of Perceptual Engineering}

Sensibility is a comprehensive psychological concept that includes sensory and visual sensation, sensory, taste, smell and touch sensory. For example, when a diner enters a restaurant, the first impression of the restaurant is observed by observing the attitude of the front attendant; after the food is eaten, the quality of the food (taste and smell) Chef's cooking (cognition), diners want to taste good food, or this restaurant is great, this feeling is emotional.

With the increasing concern about perceptuality, perceptual consumption has gradually become a 
new consumer trend, that is, consumer consumption of products and services is no longer based on good or bad social practice or social value standards, but based on Like or do not like the feeling or mood. In this period, people demand products that are no longer just real value, as well as information values, such as signs or symbols; the economy, functionality, rationality, and popularization of the product are manifested, aesthetic, Personalized replacement; product development also will be to meet the personality, happy, diverse needs of the full sense of the product as the center. As Japan's well-known designer Ping Island said in a long way, this is a shouting / material era of the end of the era of emotional era.

Consumers have a certain intention or expectation of the product before buying a product, such as practical, beautiful, upscale, refined and so on. Inductive engineering technology requires that this intention and feel be translated into a design Elements, and in the development of new products to be used. The principle of perceptual engineering is to explore the relationship between product design elements and consumer perceptual appeal to study the emotional impact of different product characteristics on the user to select the best combination of design elements to maximize consumer satisfaction The Different research institutions and scholars have also defined the perceptual engineering from different perspectives.

\section{Sensitive Engineering and Ergonomics}

From the ergonomics of the development history, meaning, and its disciplinary system, we can see that ergonomics is an important industrial design method, but it is mainly concerned about the material needs of people, that is, The degree of satisfaction with the physiological characteristics of people, the human spirit and psychological concerns are less. Faced with the current changes in consumer demand, industrial design concept of the focus has also changed, the psychological and spiritual needs of consumers is becoming the pursuit of industrial design efforts to pursue the direction. Perceptual engineering is a trend of this trend and put forward a concern about the consumer non-material needs of the design method. Sensitive engineering emphasizes consumer demand for emotional products and psychological expectations, and efforts to design products to meet the needs of these design elements to enhance consumer satisfaction. Therefore, the relationship between perceptual engineering and ergonomics can be summarized from the following aspects:

(1) Inductive engineering and ergonomics are two aspects of industrial design, the former is concerned about the consumer's non-material needs, the latter is concerned about the material needs of consumers.

(2) If the ergonomics is understood in a broad sense, the ergonomics goal is to satisfy the physical needs and psychological needs of the human art, then the perceptual work can be understood as a branch of ergonomics, Is an ergonomic design method, but more focused on the psychological needs of consumers and spiritual experience level.

(3) the fundamental purpose of the two consistent: the design concerns consumer demand, so that the design of people-oriented.

(4) the use of the two principles in the industrial design is the same, that is, by some way the consumer's feelings (physiological or psychological) translated into the product features.

(5) perceptual engineering and ergonomics are not necessarily the same object: ergonomics is concerned with the actual user, and emotional engineering is concerned about the purchaser or the user. For some products, such as machinery and equipment, collective procurement of supplies, etc., the buyer is not the final user. This will actually lead to differences in design methods and objectives in practical design. 


\section{Research on Perceptual Engineering}

Electric kettle is commonly used in small appliances, China is an important electric kettle producer and exporter, with many well-known electric kettle brand, such as the United States, Shanghai Youmei, Supor and so on. Electric kettle is generally divided into stainless steel electric kettle and plastic electric kettle. With the application of more and more widely, electric kettle technology is also mature, the current electric kettle generally have water boiling automatic shutdown function, anti-dry function and fuse protection function. The reason why this study chose electric kettle as the research object, mainly taking into account the following reasons:

(1) various brands and prices of electric kettle function is not very different, high homogeneity;

(2) consumers choose electric kettle when the emotional appeal is clear, so suitable for the use of emotional engineering for analysis;

(3) electric kettle modeling features are relatively simple, easy to deconstruction analysis;

(4) This study mainly studies the influence of the morphological design elements of the electric kettle on the sensibility of the consumers. Because of the influence of the sensibility of the color, the evaluation of the morphological design elements of the consumers will produce strong interference. Therefore, this study does not consider the electric kettle Color elements, all electric kettle pictures are processed into gray.

Collect as many product samples as possible: The selection of the final representative product samples also has a crucial impact on the scientific nature of the evaluation trials and conclusions, and therefore the product samples should be collected as much as possible at this stage. To this end, the author specifically to a number of home appliances supermarkets were electric kettle research, and through the network, magazines, product brochures and other means to sample collection, a total of 110 samples of electric kettle, in the removal of a number of similar products similar to the sample After that, the final sample of 36 samples. The electric kettle samples used in this study mainly include the products of the United States, Shanghai Youmei, Supor, Electrolux, Dragon, Kyrgyzstan and other brands.

Electric kettle characteristics analysis: a system point of view, a product can be a combination of different design features, and design features by the different design elements, which formed a different shape of the product. Electric kettle structure is relatively simple, generally by the spout, lid, pot body, handle, switch, heating base, filter and surface scale (inside the pot), power lines and other components (features).

Through the statistical analysis of the product sample characteristics and the corresponding inductive vocabulary scores, we can find out the design elements which can best explain the emotional vocabulary. For example, for the preferred vocabulary, the highest-rated product samples are Sample 1, Sample 5, and Sample 12, respectively, and the lowest scores are Sample 9, Sample 6, Sample 2, and Sample 11, respectively. For each inductive vocabulary and sample Design characteristics of a comprehensive analysis, you can find a certain correspondence between the two. For all the advantages can be summarized, in all product design features, the handle form, pot body material, pot lid form and switch position of the four characteristics of the best effect on the electric kettle, which both ends are connected with the pot body The handle is connected to the end of the handle is easy to use, stainless steel pot than the plastic material pot easy to use, lift the lid than the pick-type lid better, located in the handle at the switch is considered more than the base of the pull ring switch Easy to use, and so on. Therefore, the combination of the design elements of the electric kettle should be roughly as follows: stainless steel material + both ends of the connected handle 10 lift lid + handle button switch + cylindrical spout. The same reason can be drawn from other emotional demands of the electric kettle design elements combination. 
Applicable: pot body material, pot body, spout, pot lid and handle and other forms of its impact is relatively large, handle details and switch form of the impact of relatively small; which plastic material and streamlined pot body, cylindrical spout and An electric kettle consisting of a handle connected to a pot body at both ends is considered to be the best use. Apex: pot body material the most affected, the subjects that the plastic material of the kettle than the stainless steel material appearance; pot body, spout and pot cap shape of its impact is relatively large, and the impact of considerable degree, which geometric shape of the pot Body, cylindrical spout and lifted lid are considered more beautiful; handle details and switch form has little effect on aesthetics. High-grade: the shape of the spout, pot body form and material, as well as the handle structure of its relatively large, the lid form, handle the details of the details of the switch and its smaller; subjects that cylindrical spout, stainless steel And streamlined pot body gives the feeling of a higher level. Avant-garde: pot body material, the shape of the spout is relatively large, other effects are relatively small; stainless steel pot and cylindrical pot mouth to make the pot look more avant-garde. Interesting: pot body shape, spout form and handle details of the three design elements of the relatively large, which geometric shape of the pot body, cylindrical spout and a detailed handle design is considered more interesting. Feminization: pot body material, pot body form is relatively large, plastic material and geometry of the pot body that is more feminine features.

\section{Conclusion}

In this paper, the perceptual engineering technology is studied systematically, and a simplified model of perceptual engineering is proposed for small and medium-sized enterprises and design companies. The model is used to study the sensibility of electric kettle, which proves the validity and feasibility of perceptual engineering. In the process of the subject, the author studied a lot of Chinese and foreign literature, broadened the field of vision and knowledge, and had a strong interest in perceptual engineering, hoping to continue to study the technology, to achieve certain results, designed for our country Take off to make meager power.

\section{References}

[1] Zhang Xiaoping, Qu Shuangwei, Zhang Awei. On the user's human design [J]. Textile equipment, 2007 (06)

[2] Cai Kezhong, Shi Dazhi. The embodiment of emotional elements in the humanized design of the product [J]. Packaging Engineering, 2007 (05)

[3] Mi Baoshan, Zhou Yating. Study on the humanistic design level of the non-material society [J]. Journal of Engineering Design, 2007 (01)

[4] Kuang Junsheng, Jiang Pingyu. Design of customer customization based on perceptual engineering [J] .Journal of Computer Aided Design \& Graphiology, 2007 (02)

[5] Li Lixin. Perceptual engineering - the birth of a new discipline [J]. Art\& Life, 2006 (03) 